\title{
A ECONOMIA DESGOVERNADA
}

\section{THE DEGOVERNED ECONOMY}

\section{LA ECONOMIA DEGOVERNADA}

\section{Dowbor, Ladislau (São Paulo, São Pulo, Brasil) ${ }^{1}$}

\section{Resumo}

https://orcid.org/0000-0002-5124-1504

Está se desenhando uma catástrofe em câmara lenta, visão que já não é mais de analistas originais, mas se encontra nos escritos de pesquisadores de primeira linha mundial. A convergência dos desastres ambientais, da desigualdade explosiva, da deterioração política e do caos financeiro gerou uma atitude renovadas, de busca de novos caminhos. A pandemia que assolou o planeta apenas tornou mais urgente, e possivelmente mais viável, repensar as regras do jogo. Aqui sistematizamos alguns dos posicionamentos mais significativos, como as da Economia da Francesco, do Business Round Table com 181 das maiores corporações americanas, dos grandes grupos financeiros, do Roosevelt Institute e de numerosos cientistas sociais. Estão sendo construindo novos rumos.

Palavras-chave: crise, globalização, financeirização, pacto social

\begin{abstract}
The world is facing a slow-motion catastrophe, a vision that is not in publications of some original thinkers, but is showing up under the pen of top world researchers. The convergence of environmental disasters, explosive inequality, deteriorating politics and financial chaos has stimulated new attitudes, a search for new rules of the game. The pandemic hitting our planet only made the necessary changes more urgent, and possibly more viable. In the present paper we are presenting an overview of some of the more significative initiatives, like the Economia da Francesco by Pope Francis, 181 corporations defining new guidelines at the Business Round Table meeting, big financial corporations, the Roosevelt Institute and a number of social scientists. We are all looking for a road-map.
\end{abstract}

Keywords: Crisis, globalization, financialization, new rules

\section{Resumen}

Se está dibujando una catástrofe en cámara lenta, y esa visión ya no es de algunos analistas, sino que se encuentra em las investigaciones de autores de primera linea mundial. La convergencia de los desastres ambientales, de la desigualdad explosiva, de la deterioración política y del caos financeiro há generado actitudes renovadas, y búsqueda de nuevos caminos. La pandemia que se generalizó en el planeta le dió mayor urgencia al repensar de las reglas del juego, y posiblemente nuevas oportunidades. Aqui hemos sistematizado algunos de los aportes más significativos, como la Economia da Francesco (iniciativa del Papa Francisco), las propuestas de 181 de las mayores corporaciones norte-americanas, de los grandes grupos financieros, del Roosevelt Institute y de numerosos cientistas sociales. Se están definiendo nuevos rumbos.

Palavras-Clave: crisis, globalización, financiarización, pacto social

\footnotetext{
${ }^{1}$ Professor de Economia, Pontifícia Universidade Católica de São Paulo - PUC/SP. dowbor@org.br
} 


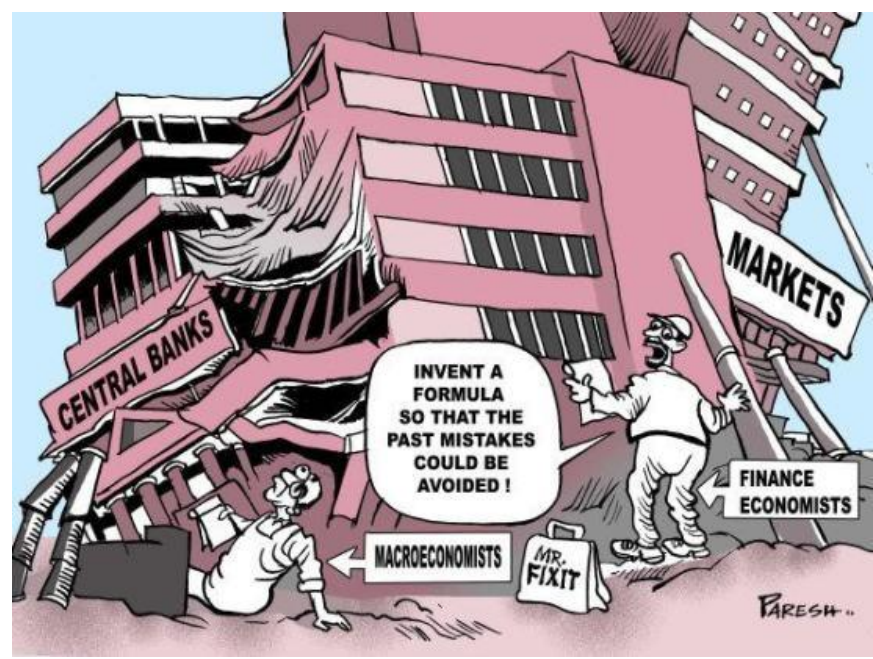

\section{Em busca do bom senso}

O Papa Francisco convocou para março de 2020 uma reunião planetária em torno de uma nova economia, chamada simbolicamente de Economia da Francesco, na linha da associação com o que seria a visão São Francisco de Assisi, aliás local da reunião proposta. Gerou-se com isso um amplo movimento, por parte de comunidades de diversas religiões, e ampliou-se a visibilidade com a participação direta de personagens como Jeffrey Sachs, Joseph Stiglitz, Amarty Sen, Vandana Shiva, Mohammad Yunus, Kate Raworth e outros personagens de primeira linha mundial, com forte presença de prêmios Nobel. Uma ideia básica, de que a economia deve servir à sociedade, e não o contrário, está encontrando um eco profundo. Vivemos uma era de profunda insegurança e busca de novos modelos. $O$ atual não funciona.

\section{A iniciativa Economia de Francisco (www.francescoeconomy.org) tem como} objetivo

trazer gente jovem, além das diferenças de crenças ou nacionalidade, para um acordo (agreement) no sentido de repensar a economia existente, e de humanizar a economia de amanhã: torná-la mais justa, mais sustentável, assegurando uma nova preeminência para as populações excluídas.

Today more than ever, everything is deeply connected and that the safeguarding of the environment cannot be divorced from ensuring justice for the poor and finding answers to the structural problems of the global economy. We need to correct models of growth incapable of guaranteeing respect for the environment, openness to life, concern for the family, social equality, the dignity of workers and the rights of future generations. Sadly, few have heard the appeal to acknowledge the gravity of the problems and, even more, to set in place a new economic model, the fruit of a culture of communion based on fraternity and equality. ${ }^{2}$

2"To embrace young people, beyond differences in belief and nationality, an agreement to change the current economy and humanize the economy of tomorrow: to make it more just, more sustainable and to give new prominence to excluded people." https://francescoeconomy.org/wp-content/uploads/2019/08/PR EconomyOfFrancesco $082019 . p d f$ A carta 
No conjunto, trata-se de repensar a função da economia na sociedade. Afinal, a economia em princípio deve servir para vivermos melhor, e não para que estejamos a seu serviço. Parece que está se chegando a uma visão de bom senso, um reordenar dos argumentos. Uma economia a serviço do bem comum implica que seja economicamente viável, mas também socialmente justa e ambientalmente sustentável. Este triplo objetivo define um novo equilíbrio e uma outra forma de organização.

O desafio não é o de falta de recursos. No mundo se produz anualmente 85 trilhões de bens e serviços por ano, o que, razoavelmente distribuído, asseguraria 15 mil reais por mês por família de quatro pessoas. E o Brasil está precisamente nesta média mundial. O que hoje produzimos é amplamente suficiente para uma vida digna e confortável para todos. Nosso problema não é de capacidade de produção, e sim de saber o que produzimos, para quem, e com que impactos ambientais. O grande desafio é o da governança do sistema, desafio sem dúvida técnico, mas sobretudo ético e político.

O mundo que enfrentamos se caracteriza por crescente e dramática desigualdade, com $1 \%$ detendo mais riqueza do que os $99 \%$ seguintes, e 26 famílias com mais do que a metade mais pobre da população, 3,8 bilhões de pessoas. No Brasil 6 famílias acumularam mais riqueza do que os 105 milhões na base da pirâmide. A desigualdade atingiu níveis eticamente, politicamente e economicamente insustentáveis.

A mudança climática, a liquidação da vida nos mares e em terra - perdemos $52 \%$ dos vertebrados em apenas 40 anos - a perda de cobertura florestal, a contaminação química generalizada, a inundação dos plásticos e tantos outros processos destrutivos estão levando a uma catástrofe ambiental generalizada.

Temos assim de enfrentar o duplo desafio da redução da desigualdade, portanto de uma democratização da economia, e da redução do ritmo de destruição da base natural da nossa sobrevivência, evoluindo para uma economia circular sustentável.

Sabemos o que deve ser feito: os 17 objetivos do desenvolvimento sustentável (Agenda 2030) o definem claramente. Temos os recursos financeiros: apenas nos paraísos fiscais, os 20 trilhões de dólares que resultam de evasão fiscal, corrupção e lavagem de dinheiro, representam 200 vezes os 100 bilhões que na Conferência de 2015 
em Paris se decidiu alocar para as políticas ambientais. Temos grande riqueza de informações sobre cada problema do planeta, os dramas estão localizados e quantificados. E temos também as tecnologias que hoje permitem transitarmos para outras matrizes de transporte, de energia, e dos próprios processos produtivos. Não é, portanto, uma questão de falta de meios, e sim de profundas deformações políticas de como gerimos as nossas economias.

Assim, o desafio está no próprio processo decisório, em como definimos, regulamos e orientamos o uso dos nossos recursos. A economia tem de voltar a servir o bem comum. Nas discussões preliminares de preparação da participação brasileira no evento, mais do que elencar as desgraças que nos atingem, buscamos nos concentrar nos desafios organizacionais, de governança, que permitam resgatar os rumos, de parar de destruir o planeta em proveito de uma minoria que acumula capitais improdutivos.

Os pontos essenciais que sugerimos para discussão, em torno desta Economia de Francisco, são os seguintes:

1) Democracia econômica: trata-se de resgatar a governança corporativa, sistemas transparentes de informação, e de gerar maior equilíbrio entre o Estado, as corporações e as organizações da sociedade civil. Não haverá democracia política sem democracia econômica.

2) Democracia participativa: os processos decisórios sobre como definimos as nossas opções, como priorizamos o uso dos nossos recursos, não podem depender apenas de um voto a cada dois ou a cada quatro anos. Com sistemas adequados de informação, gestão descentralizada e ampla participação da sociedade civil organizada precisamos alcançar um outro nível de racionalidade na organização econômica e social. As novas tecnologias abrem imensos potenciais que se trata de explorar.

3) Taxação dos fluxos financeiros: essencial para assegurar a informação sobre os capitais especulativos, e para que os recursos financeiros sirvam para financiar tanto a redução da desigualdade como para estimular processos produtivos sustentáveis. $\mathrm{Na}$ realidade os sistemas tributários no seu conjunto devem servir ao maior equilíbrio distributivo e à produtividade maior dos recursos.

4) Renda básica universal: no quadro de uma visão geral de que algumas coisas não podem faltar a ninguém, uma forma simples e direta, em particular com as técnicas modernas de transferência, é assegurar um mínimo para cada família. Não se 
trata de custos, pois a dinamização do consumo simples na base da sociedade dinamiza a economia e gera o retorno correspondente.

5) Políticas sociais de acesso universal, público e gratuito: o acesso à saúde, educação, cultura, segurança, habitação e outros itens básicos de sobrevivência devem fazer parte das prioridades absolutas. Não se trata de custos, e sim de investimentos nas pessoas, que dinamizam a produtividade e liberam recursos das famílias para outras formas de consumo.

6) Desenvolvimento local integrado: somos populações hoje essencialmente urbanizadas, e o essencial das políticas que asseguram o bem-estar da comunidade e 0 manejo sustentável dos recursos naturais deve ter raízes em cada município, construindo assim o equilíbrio econômico, social e ambiental na própria base da sociedade.

7) Sistemas financeiros como serviço público: o dinheiro que manejam os sistemas financeiros tem origem nas nossas poupanças e impostos, constituem recursos do público, e neste sentido devem responder às necessidades do desenvolvimento sustentável. Bancos públicos, bancos comunitários, cooperativas de crédito e outras soluções, como moedas virtuais diversificadas, são essenciais para que as nossas opções tenham os recursos correspondentes.

8) Economia do conhecimento: o conhecimento hoje constitui o principal fator de produção. Sendo imaterial, e indefinidamente reproduzível, podemos gerar uma sociedade não só devidamente informada, mas com acesso universal e gratuito aos avanços tecnológicos de ponta. Temos de rever o conjunto das políticas de patentes, copyrights, royalties de diversos tipos que travam desnecessariamente o acesso aos avanços. O conhecimento é um fator de produção cujo uso, contrariamente aos bens materiais, não reduzem o estoque.

9) Democratização dos meios de comunicação: os recentes avanços do populismo de direita e a erosão dos processos democráticos mostram a que ponto 0 oligopólio dos meios de comunicação gera deformações insustentáveis, climas de exacerbamento de divisões e aprofundamento de ódios e preconceitos. Uma sociedade informada é absolutamente essencial para o próprio funcionamento de uma economia a serviço do bem comum.

10) Pedagogia da economia: a economia consiste essencialmente em regras do jogo pactuadas pela sociedade ou impostas por grupos de interesse. A 
democracia econômica depende vitalmente da compreensão generalizada dos mecanismos e das regras. Os currículos obscuros e falsamente científicos têm de ser substituídos por ferramentas de análise do mundo econômico real, de maneira a formar gestores competentes de uma economia voltada para o bem comum.

Esses eixos de análise se referem essencialmente ao processo decisório, às ferramentas de governança de que a sociedade deve dispor para resgatar a funcionalidade dos sistemas econômicos. Neste sentido, são aplicáveis tanto às atividades produtivas como indústria e agricultura, como a políticas sociais como saúde e educação e assim por diante. A filosofia geral aqui proposta consiste na compreensão de que democracia política sem democracia econômica não funciona: os dois universos devem resgatar a sua coerência. E frente ao aprofundamento dos desastres sociais, ambientais, políticos e econômicos, não só o tempo urge, como começamos a ver uma ampla mudança de atitudes, ou pelo menos uma tomada de consciência.

Há amplos caminhos sendo traçados por pesquisadores e centros de pesquisa, e pode-se dizer que estão sendo construídas de forma muito dinâmica as bases teóricas de uma outra economia. Ultrapassando os antigos debates entre ortodoxia e heterodoxia nas teorias econômicas, surge um novo pragmatismo, desta vez baseado em valores, no sentido de se buscar o que funciona, independentemente das eternas etiquetas ideológicas. Veremos abaixo algumas amostras da discussão mundial que se generaliza.

\section{Mea Culpa}

Em setembro de 2019, 181 das maiores corporações mundiais assinaram uma carta de compromisso, redefinindo os seus objetivos, e deixando formalmente de lado 0 que foi o seu credo durante décadas, de que devem enriquecer os seus acionistas e se despreocupar das consequências sistêmicas, qualificadas comodamente de "externalidades". Negociado e divulgado no quadro do BRT (Business Round Table), o texto é curto, são basicamente cinco parágrafos, mas que reproduzimos aqui no original, atualizado em 6 de setembro de 2019: ${ }^{3}$

While each of our individual companies serves its own corporate purpose, we share a fundamental commitment to all of our stakeholders. We commit to:

- Delivering value to our customers. We will further the tradition of American companies leading the way in meeting or exceeding customer expectations.

3 Released: August 19, 2019 Updated with New Signatures: September 6 , 2019 file://C:/Users/Ladislau\%20Dowbor/Downloads/BRT-Statement-on-the-Purpose-of-a-Corporation-with-Signatures-1.pdf 


\begin{abstract}
- Investing in our employees. This starts with compensating them fairly and providing important benefits. It also includes supporting them through training and education that help develop new skills for a rapidly changing world. We foster diversity and inclusion, dignity and respect.

- Dealing fairly and ethically with our suppliers. We are dedicated to serving as good partners to the other companies, large and small, that help us meet our missions.

- Supporting the communities in which we work. We respect the people in our communities and protect the environment by embracing sustainable practices across our businesses.

- Generating long-term value for shareholders, who provide the capital that allows companies to invest, grow and innovate. We are committed to transparency and effective engagement with shareholders. Each of our stakeholders is essential. We commit to deliver value to all of them, for the future success of our companies, our communities and our country.
\end{abstract}

Ou seja, responder às expectativas dos consumidores, sem dúvida, mas também investir na promoção dos seus empregados - surgem palavras como "diversidade e inclusão, dignidade e respeito" - o que gera expectativas para quem acompanha como é trabalhar na Walmart ou na Amazon, ou ainda nas linhas de montagem da Apple na China. O compromisso de lidar eticamente com os fornecedores, grandes ou pequenos, seria também uma inovação radical. O quarto ponto, de se responsabilizar com os impactos que exercem sobre as comunidades e o meio ambiente, assumindo a sustentabilidade como objetivo, é evidentemente essencial, mas talvez 0 mais transformador seja o quinto, em que se ambiciona sim continuar a gerar valor para os acionistas, mas no quadro de uma visão sistêmica que envolve compromissos com o longo prazo e os efeitos sobre as comunidades, quando sabemos que a cultura atual é de se assegurar a maximização de retornos no curto prazo, com pouca preocupação com os resultados para a sociedade.

Nada de profundamente revolucionário na aparência, simples bom senso, mas depois de 40 anos em que as corporações se esconderam por trás das teorias tão convenientes de Milton Friedmann - "The business of business is business" - portanto tendo como único dever enriquecer os acionistas, esta carta de intenções impressiona. Os grandes conglomerados decidem alterar os rumos. Ou assim o declaram.

Conhecendo as corporações, Joseph Stiglitz (2019) reage com otimismo moderado:

Nas últimas quatro décadas, a doutrina prevalecente nos EUA tem sido a de que as corporações devem potencializar os valores para seus acionistas - isto é, aumentar os lucros e os preços das ações - aqui e agora, não importa o que aconteça, sem se preocupar com as consequências para os trabalhadores, clientes, fornecedores e comunidades. Logo, a declaração que defende um capitalismo consciente e que foi assinada este mês por quase todos os 
membros da Business Roundtable causou um grande alvoroço. Afinal de contas, trata-se dos executivos-chefes das companhias mais poderosas dos EUA, dizendo aos norte-americanos que o mundo dos negócios é muito mais do que apenas balanços patrimoniais. E isso é uma baita virada de jogo, não é mesmo?

Parece adequado este otimismo cauteloso. Mas a realidade é que ver, no fim da carta, as assinaturas do Bezos da Amazon, e dos CEOs das maiores corporações como Apple, Johnson\&Johnson, CityGroup e tantos outros, com um posicionamento que reverte profundamente o que nos foi repetido durante décadas, chama a atenção. Essas quase 200 corporações se reunirem para uma tomada pública de posição de que deverão assumir suas responsabilidades indica em todo caso que estão sentindo uma mudança nos tempos, reflexo de um despertar de indignações planetárias com o caos que está sendo gerado.

\section{Mea Maxima Culpa}

Mais interessante ainda é a tomada de posição de 130 dos maiores bancos do mundo, que proclamam o seu propósito de respeitar seis princípios básicos: ${ }^{4}$ deverão alinhar as suas atividades com os Objetivos de Desenvolvimento Sustentável, inclusive os compromissos climáticos de Paris; assegurar um sistema aberto de avaliação dos impactos dos financiamentos; encorajar atividades sustentáveis por parte dos seus clientes; definir objetivos sociais em consulta com os diversos atores sociais; assegurar uma governança interna responsável; gerar instrumentos de transparência para que possam ser verificados os efeitos das suas atividades sobre a sociedade.

Lembremos que os 130 bancos signatários representam ativos de 47 trilhões de dólares, quando o PIB mundial, para termos uma referência, é de 85 trilhões. Ver a assinatura de grandes agiotas como os nossos principais bancos brasileiros na lista gera evidente ceticismo.

\footnotetext{
${ }^{4}$ Banking Principles - UNEP - 23 sept. 2019 - Ativos de 47tri\$ https://www.unepfi.org/banking/bankingprinciples/ The Principles for Responsible Banking - See also: https://www.unepfi.org/news/industries/banking/130-banks-holdingusd-47-trillion-in-assets-commit-to-climate-action-and-sustainability/
} 


\begin{tabular}{|c|c|c|}
\hline $\begin{array}{l}\text { PRINCIPLE1: } \\
\text { We will align our business strategy to } \\
\text { be consistent with and contribute to } \\
\text { individuals' needs and society's goals, as } \\
\text { expressed in the Sustainable Development } \\
\text { Goals, the Paris Climate Agreement and } \\
\text { relevant national and regional frameworks. }\end{array}$ & $\begin{array}{l}\text { PRINCIPLE2: } \\
\text { IMPACT \& } \\
\text { TARGET SETTING } \\
\text { We will continuously increase our positive } \\
\text { impacts while reducing the negative } \\
\text { impacts on, and managing the risks to, } \\
\text { people and environment resulting from our } \\
\text { activities, products and services. To this } \\
\text { end, we will set and publish targets where } \\
\text { we can have the most significant impacts. }\end{array}$ & $\begin{array}{l}\text { PRINCIPLE: } \\
\text { CLIENTS \& } \\
\text { CUSTOMERS }\end{array}$ \\
\hline $\begin{array}{l}\text { PRINCIPLE4: } \\
0.0 \\
0.0 \\
0.0\end{array}$ & $\begin{array}{l}\text { PRINCIPLE 5: } \\
\text { GOVERNANCE } \\
\text { \& CULTURE }\end{array}$ & $\begin{array}{l}\text { PRINCIPLE: } \\
\text { TRANSPARENCY \& } \\
\text { ACCOUNTABILITY } \\
\text { We will periodically review our individual } \\
\text { and collective implementation of these } \\
\text { Principles and be transparent about and } \\
\text { accountable for our positive and negative } \\
\text { impacts and our contribution to society's } \\
\text { goals. }\end{array}$ \\
\hline
\end{tabular}

E o fato é que as grandes corporações atuam no espaço planetário, onde não há governo, regulação ou regras do jogo. As maiores simplesmente não pagam impostos, como é o caso no Brasil com a isenção de imposto sobre lucros e dividendos distribuídos. (Lei de 1995). Os desastres ambientais e sociais estão se generalizando, a desigualdade atinge níveis explosivos, mas os bancos vão bem. Em paraísos fiscais temos 200 vezes mais recursos financeiros do que o a Conferência Mundial sobre o Clima decidiu, e mal consegue, levantar. Fraudes em medicamentos, alimentos que generalizam a obesidade, inclusive infantil, trambiques em emissões de veículos, agrotóxicos e antibióticos nos alimentos - é um clima de vale-tudo, pois a remuneração dos juros bancários e dos aplicadores financeiros como acionistas e outros fundos têm prioridade absoluta no direcionamento dos recursos.

A verdade é que a indignação está se generalizando. Os impactos econômicos, ambientais e sociais que as corporações provocam fazem parte das suas responsabilidades. Após 40 anos de neoliberalismo irresponsável, há novos caminhos? É saudável recebermos a notícia com ceticismo, a cosmética corporativa tem longa tradição. Mas também é fato que pelo jeito as corporações, e em particular os bancos, estão sentindo o calor da irritação social, enquanto os desastres se tornam cada vez mais visíveis, gerando protestos cada vez mais amplos. 
As amplas movimentações, como o chamado do Papa Francisco, as manifestações populares como hoje vemos se expandindo, e as proclamações defensivas do mundo corporativo - abrem espaço para um conjunto de aportes teóricos que reformulam a economia tal como tem sido formulada e ensinada, e que agora adquirem grande visibilidade. São visões comodamente classificadas de "heterodoxas", mas que funcionam, contrariamente às visões ditas ortodoxas que essencialmente justificam os interesses corporativos, e nos levaram aos impasses atuais.

\section{Novas regras do jogo 5}

Uma iniciativa importante me parece ser o estudo do Roosevelt Institute, New Rules for the 21st Century, novas regras para o século 21. Uma constatação forte dá o tom: "Entregamos os nossos governos aos mercados, e entregamos os mercados às corporações". (p. 8)

Um choque impressionante de realismo caracteriza esta excelente síntese dos novos caminhos que os Estados Unidos precisam trilhar para que a economia volte a servir a sociedade, não o contrário. Aqui também temos um aporte propositivo, uma sistematização dos principais desafios e medidas a tomar. O Roosevelt Institute se caracteriza pela seriedade das suas pesquisas e o bom senso das propostas:

O presente relatório vai ilustrar a necessidade crucial de se reduzir o poder corporativo e resgatar o poder público. Mostraremos que ambos são necessários para mover nossa nação para um futuro que se apoia no que houve de melhor na nossa história, corrige erros cometidos e se adapta aos tempos modernos." (p. 10)

O relatório impressiona também por fugir de simplificações ideológicas, buscando claramente as medidas cuja utilidade já foi comprovada. E ajuda muito a clareza ao mostrar as dimensões políticas, de poder de decisão efetivo sobre o uso dos recursos, que temos de enfrentar. O problema não está na falta de recursos, e sim no seu desvio por corporações que em vez de fomentar a economia a drenam, apropriando-se para este fim das próprias políticas públicas. Ou seja, o relatório enfrenta a questão central. E esta questão, evidentemente, não se limita aos Estados Unidos.

As generalizações sobre a ineficiência do governo e sua pouca efetividade são exageradas (overblown), enquanto as consequências negativas das soluções

5 Roosevelt Institute - New Rules for the 21st Century - 2019 - 77p. https://rooseveltinstitute.org/wpcontent/uploads/2019/04/Roosevelt-Institute 2021-Report Digital-copy.pdf 
baseadas no mercado têm sido muito frequentemente desconsideradas...A América deixou de lado um poderoso instrumento de governo: a provisão pública direta de bens e serviços. (p. 47-48)

Ou seja, o que sentimos no relatório, é que finalmente a onda neoliberal está refluindo já não em rincões da esquerda, mas em instituições de grande peso.

Nos últimos 50 anos, temos desinvestido (disinvested) do poder público e nos temos dito que o governo é o problema. Sabemos que isso está errado. Sabemos também que o governo é a base para as instituições e os bens tangíveis que constituem o tecido das nossas vidas cotidianas - escolas e segurança pública; estradas e pontes; alimentos e medicamentos mais saudáveis; ar e água mais limpos. (p. 63)

Fugindo das polarizações, o relatório mostra que o fortalecimento da capacidade de governo é central inclusive para o funcionamento da economia em geral.

O efeito combinado de poder corporativo concentrado e do poder público corrompido tem sido devastador para o nosso país... O governo não está investindo na população, nos programas públicos, na tecnologia ou na infraestrutura física - o tipo de investimentos que uma economia forte e em expansão exige. (p. 21)

Lembremos que no Brasil 'investir na população' é qualificado de 'gasto'.

Não se trata aqui de algum flerte com socialismo. Trata-se, na minha interpretação, de um choque de realismo para que o próprio capitalismo volte a funcionar. Tenho qualificado essa busca de 'capitalismo civilizado'. O próprio documento sugere uma 'visão de mundo progressiva' (progressive world-view). Mas as propostas destoam profundamente do neoliberalismo:

\begin{abstract}
A história não tem sido caridosa com o neoliberalismo, esse caótico saco de ideias baseadas na noção fundamentalista de que os mercados se auto-corrigem, alocam recursos com eficiência, e servem bem o interesse público. Aprender a lição de que o neoliberalismo sempre foi uma doutrina política a serviço de interesses especiais pode constituir o fio condutor na nuvem que hoje recobre a economia global. (p. 1)
\end{abstract}

Leram bem, um documento assinado entre outros por quem já foi economista chefe do governo Clinton e do Banco Mundial.

Os interesses especiais, obviamente, são as corporações, que se transformaram numa máquina rentista, que extrai da economia em vez de contribuir:

Como tanto poder das corporações é direcionado para "extração de renta" (rentextraction, aspas dos autores), - tomar uma parte maior do bolo econômico da nação ao tirar vantagens de outros - em vez de criar riqueza, reduzir o poder corporativo vai inclusive fortalecer o conjunto da economia. (p. 3) 
Temos aqui a evidente consequência da financeirização. $O$ processo se agravou com a apropriação da política:

No final, isso permitiu que os muito ricos convertessem o seu poder econômico em poder político concentrado que, por sua vez, permitiu que eles torcessem ainda mais as regras a seu favor e capturassem mais poder econômico. (p. 7)

É a máquina infernal: poder financeiro que gerou poder político, que por sua vez permite torcer as leis para gerar mais poder financeiro.

Assim, "este vale-tudo do setor privado prejudicou o bem-estar dos indivíduos e das comunidades pelos Estados Unidos afora, mas também travou o crescimento econômico, já que permitiu que os super-ricos retirem lucros do rentismo e de outras atividades que aumentam a sua riqueza sem fazer a economia crescer. " (p. 7) O sistema descolou claramente das contribuições produtivas:

Markups, ou seja, o montante que a companhia cobra acima dos custos, aumentaram de $18 \%$ acima do custo marginal em 1980, para $67 \%$. Isso sugere que os lucros corporativos compreendem não retornos produtivos sobre o capital e o trabalho, mas rentas. (p. 10) 6

Ou seja, remuneramos essencialmente aplicações financeiras, não investimentos: "Antes de 1970, as corporações americanas pagavam $50 \%$ dos seus lucros aos acionistas e o resta era reinvestido no negócio. Hoje, o pagamento aos acionistas está na ordem de $90 \%$ dos lucros declarados (Mason 2015a)." (p. 17)

O relatório tira as consequências em termos de resgate da produtividade do setor financeiro.

Para assegurar que a função das finanças seja socialmente benéfica, a reforma do setor financeiro devera buscar, acima de tudo, reduzir os riscos macroeconômicos e limitar as práticas predatórias. Além disso, as reformas deveriam buscar o aumento do crédito produtivo, que poderia estimular pequenos negócios que atualmente enfrentam limitações de capital, facilitar empréstimos simples eficientes e a baixo custo, e servir as famílias não bancarizadas ou insuficientemente bancarizadas que atualmente estão sendo exploradas por financeiras de alto custo. (p. 39)

No nosso caso brasileiro, evidentemente, os próprios bancos fazem o papel de agiotas, em escala incomparavelmente mais nociva. Mas é útil ver que o problema do resgate da utilidade social e econômica dos intermediários financeiros seja colocada com clareza.

Apesar dos avanços tecnológicos que deveriam ter tornado a indústria das finanças - um serviço de 'intermediação' - menos caro e mais competitivo com o

\footnotetext{
${ }^{6}$ Estou aqui traduzindo rent por renta, pois não é possível que não tenhamos a palavra correspondente em português. Temos sim rentismo, mas falamos que alguém "vive de rendas" quando se trata de rendimentos improdutivos. Em inglês "rent" e "income" são claramente diferentes, como também em francês, "rente" e "revenu".
} 
tempo, o custo unitário das finanças hoje é tão caro como era em 1900, porque o setor financeiro não repassa essas economias para os consumidores e sim para aumentar os lucros. (p. 24)

Os autores salientam inclusive o fato que a existência de um forte sistema financeiro público é essencial para estimular a qualidade dos serviços prestados pelos mercados: "O provimento público de serviços financeiros básicos não constitui um defeito, mas precisamente o objetivo. Essencialmente, haver uma alternativa pública tende a disciplinar os mercados para assegurar o acesso, qualidade e quantidade de bens e serviços essenciais." (p. 54) Ou seja, precisamos não só de regulação, mas de empresas públicas que forneçam diretamente bens e serviços para servir de contrapeso, abrindo alternativas para a população e colocando limites à agiotagem e rentismo financeiro. Para nós, que estamos atolados em negociatas de privatização, é importante esta compreensão de que a existência do setor público provedor de serviços é essencial para tornar o setor privado mais performante.

O documento no seu conjunto buscar resgatar o papel do setor público.

Os agentes políticos (policymakers) deveriam expandir o poder do governo, ao prover diretamente as políticas, com dois objetivos na linha de frente de uma nova visão de mundo progressiva: acesso universal aos bens e serviços e investimentos transformadores na busca de objetivos nacionais. (p. 51)

Invertendo as narrativas neoliberais, o texto mostra a maior produtividade sistêmica alcançada quando o governo assume um papel de provedor direto de políticas. E mostra a falácia da chamada austeridade: "Na realidade, está comprovado que gastar pouco demais leva no fim das contas a custos muito mais elevados (em termos de prejuízo para a vida das pessoas e para o crescimento econômico) do que gastar demais." (p. 13)

No Brasil, sentimos isso na pele, na medida em que o travamento do acesso às políticas públicas força as pessoas a recorrer a serviços privados muito mais caros, resultando em perda de produtividade sistêmica. É bom lembrar que durante os anos 2003 a 2013, que o Banco Mundial qualificou de "década dourada" (Golden Decade) da economia brasileira, houve forte expansão de renda e de acesso a bens e serviços públicos, o que dinamizou o a economia e limitou o déficit, pois gerou aumento de receitas. O déficit se torna significativo a partir da era da austeridade de 2014 em diante. Para o detalhe, veja o capítulo 12 do meu $A$ Era do Capital Improdutivo, disponível em http://dowbor.org .

A política pública, executada com cuidado relativamente às dinâmicas de mercado subjacentes, deveria constituir o mecanismo básico (default mechanism) para 
prover bens e serviços que são essenciais para a dignidade e atuação humanas, tais como acesso à habitação, cuidados de saúde, e serviços bancários. O provimento público direto dos serviços é essencial em casos em que o público tem um forte interesse em ter acesso universal, e em que os setores privados têm como exercer um poder de mercado sobre os que buscam acesso. Há justificações econômicas para utilizar o poder do governo para prover bens e serviços essenciais. Uma vasta literatura mostra os benefícios econômicos de se assegurar um nível básico de serviços que incluem o cuidado infantil, a educação inicial e aposentadorias. Particularmente significativo é o fato que um maior investimento nas pessoas assegura uma maior produtividade econômica no conjunto. (p. 52)

As mudanças, na visão dos autores, não se darão sem uma transformação do processo decisório nas próprias corporações, na chamada governança corporativa.

Para se criar um sistema que sirva aos interesses de todos os atores interessados (stakeholders), e não só dos executivos e da comunidade de aplicações financeiras, deveria ser exigido dos conselhos de administração das corporações a inclusão, no mínimo, de uma proporção substantiva de trabalhadores bem como de representantes de outros stakeholders que não sejam acionistas. (p. 37)

O texto mostra como isso funciona na Alemanha e outros países. O relatório recomenda inclusive o reforço dos próprios mecanismos de regulação. Em particular, explicita como funciona o sistema de proteção do consumidor de serviços financeiros (Consumer Financial Protection Bureau: CFBR) "que materializou a visão de um governo federal que serve e reforça a democracia, e é fortemente apoiado pela população." (p. 43). E explicita as necessidades de uma transformação da política tributária: "Elevar as alíquotas tributárias marginais no topo e taxar rendimentos de capital permitiria extrair mais recursos que as firmas usam para pagar aos acionistas e executivos (CEOs)." (p. 60). Não custa lembrar aqui que o CEO da Disney embolsou um salário equivalente a cerca de 1500 vezes o salário médio dos seus empregados, provocando inclusive indignação de uma das netas do Disney. O executivo em questão não tem 1500 vezes mais filhos para criar. Aqui não trata de exageros pontuais, mas de uma deformação patológica do sistema.

Igualmente interessante é a proposta de uma política pro-ativa de inclusão produtiva. "Uma política de garantia federal de emprego (Federal Jobs Guarantee - FJG) constituiria uma fonte direta de empregos com poder público de literalmente terminar com o desemprego involuntário e pobreza de trabalho." (p. 57) Tal política poderia assegurar que

independentemente de falhas de mercado - tais como choques econômicos, acordos comerciais mal planejados, discriminação estrutural - cada americano teria o direito a um emprego e à renda e dignidade associadas com o trabalho. Uma garantia de emprego poderia funcionar como uma opção pública que coloca uma regra básica para benefícios, compensações e práticas equitáveis que formatariam o mercado de trabalho no seu conjunto. (p. 61) 
Claramente, na visão dos autores, o enfoque econômico não é suficiente. Para as necessidades básicas humanas, temos de nos voltar para o 'argumento dos direitos'. Mas mesmo em termos macroeconômicos, temos de inverter o raciocínio: "É muito mais provável que o problema que temos de enfrentar seja de demanda agregada inadequada e desemprego elevado, do que sobreaquecimento e inflação." (p. 58) Expandir a demanda agregada, evidentemente, melhora a situação das famílias e reduz o desemprego. Nada de radicalmente novo aqui, mas sim muito bom senso. Adeus austeridade.

Volto a mencionar que não se trata, nesta análise do Roosevelt Institute, de propor rupturas sistêmicas, e sim de civilizar o processo. Para nós, que nos debatemos no primitivismo ideológico e em narrativas absurdas de que sacrificar a população é "ao fim e ao cabo" bom para ela, vejo este documento como extremamente útil. Qual que seja o realismo das propostas, o desmonte do sistema por uma instituição que está no coração dele, com argumentos muito bem organizados, ajuda muito. Não é crítica externa por opositores, é um choque interno de lucidez, por parte de quem conhece o sistema em profundidade. Francamente, são sessenta e poucas páginas que constituem um excelente custo-benefício. Só para não esquecer: a bibliografia é ótima, com artigos e estudos disponíveis online, de acesso aberto e imediato. Para quem quer aprofundar, uma ferramenta.

\title{
Corrigir as contas da economia
}

Kate Raworth (2017) é uma das participantes diretas da Economia da Francesco. O aporte fundamental dela é uma revisão radical de como fazemos as contas na economia, ultrapassando as profundas deformações do cálculo do PIB, que calcula apenas a velocidade dos fluxos econômicos, mas não nos informa sobre os resultados para a sociedade, que é precisamente o que queremos de uma economia que funcione. George Monbiot $^{7}$, do Guardian, não exagera:

\begin{abstract}
Eu li este livro com a excitação com que as pessoas do seu dia devem ter lido a Teoria Geral de John Maynard Keynes. É brilhante, entusiasmante e revolucionário. Com um poço profundo de aprendizagem, sabedoria, e pensamento profundo, Kate Raworth redesenhou e redefiniu os marcos da teoria econômica. É completamente acessível, mesmo para pessoas sem conhecimento do assunto. Eu acredito que Doughnut Economics vai mudar o mundo.
\end{abstract}

\footnotetext{
7 Para a resenha feita pelo próprio Monbiot, no Guardian, veja http://www.monbiot.com/2017/04/13/circle-of-life/
} 
Comentário forte, mas perfeitamente adequado.

De forma simples e direta, Raworth faz um tipo de "reset" de como vemos o mundo econômico, e a nova visão faz todo sentido. Consciente de que precisamos hoje, mais do que do detalhe, de uma imagem de referência sobre o que queremos da economia, a autora substitui os nossos tradicionais gráficos de fluxos por uma imagem, o doughnut, a nossa familiar rosquinha. Vale a pena se apropriar de uma ideia básica, de que estamos produzindo algumas coisas em excesso, como poluição do ar, e outras de forma insuficiente, como educação e saúde. Os excessos aparecem como explodindo para além da rosca, e as insuficiências como que não chegam à rosca, ficam no vazio interno.

Com esse desenho simples estamos saindo da síntese quantitativa do PIB, em que a destruição ambiental como desmatamento ou vazamentos de petróleo aparecem como positivos, pois aumentam as atividades e logo o PIB. Evoluímos para uma conta completa, permitindo identificar o que tem de ser controlado, por exemplo a contaminação química, e o que tem de ser expandido, por exemplo o acesso aos alimentos. Entramos assim na economia do bom senso. Só lembrando a tão bela frase que encontrei num banner de estudantes de economia: "Crescer por crescer, é a filosofia da célula cancerosa". Portanto, temos aqui um ponto de partida sobre o qual podemos construir as políticas, organizar estímulos ou regulação, e repensar as nossas teorias.

O bom do Donut, como todos sabem, é o concreto, aquela rodinha onde tem a massa e o açúcar em cima. No limite interno da rosca, para dentro do vazio, ficam as insuficiências, que devem ser sanadas: 12 itens como alimento, saúde, educação, emprego e renda, paz e justiça, voz política, equidade social, igualdade de gênero, habitação, redes, energia e água. No corpo da rosca, é o espaço onde devemos nos situar, dimensão justa e segura para a humanidade. No limite externo da rosca, fica o teto ecológico que não deveríamos ter ultrapassado: são 9 itens, envolvendo mudança climática, acidificação dos oceanos, poluição química, sobrecarga de nitrogênio e de fósforo, extração de água doce, conversão do solo, perda de biodiversidade, poluição do ar, e destruição da camada de ozônio. 


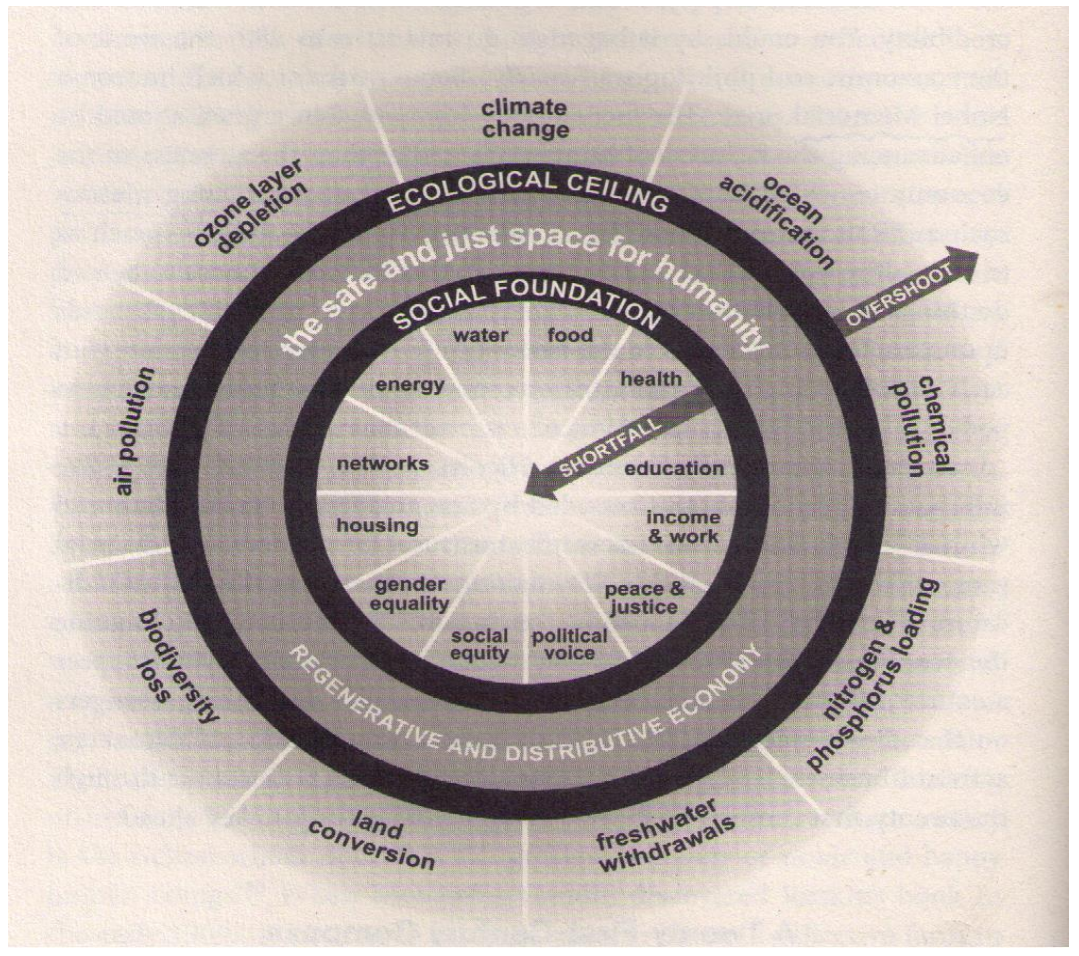

Ou seja, no vazio interno da rosca, temos as insuficiências, shortfall, o que tem de melhorar para entrar no espaço seguro da própria donut. E no vazio externo, temos os excessos, o overshooting, que temos de reduzir. Não muito diferente de como cuidamos da casa, em que temos de complementar as insuficiências, e controlar os excessos. A economia deixa de ser um mistério para amadores de modelos matemáticos, e passa a fazer sentido para os comuns dos mortais. Ao mesmo tempo, temos uma imagem simples e desafios que são coerentes com o que foi decidido nas grandes conferências de 2015, com o Acordo de Paris e os Objetivos do Desenvolvimento Sustentável, a Agenda 2030, em Nova lorque. (p. 38-39)

A simplicidade e facilidade de leitura, inclusive de visualização mental, dos desafios econômicos, é essencial, pois enquanto a imensa maioria da população não entender a lógica de como usamos os nossos recursos, as farsas irão continuar. Inclusive a farsa maior, de que precisamos dos ricos pois eles investem e geram empregos, e de que precisamos de pobres pois a pobreza os leva a trabalhar. Na realidade os ricos hoje fazem aplicações financeiras em vez de investir, colocam os recursos em paraísos fiscais e, portanto, pouco investem, e mal pagam os seus impostos. Num mundo que funcione, impostos sobre o capital improdutivo levará os rentistas a buscar fazer algo de útil com os 
seus capitais. E como constatamos em qualquer iniciativa que assegurou mais recursos para a população, o resultado é maior demanda, multiplicação de pequenas e médias empresas e expansão do emprego. O que aliás gera maior massa de impostos e equilíbrio de contas públicas. Veja-se o sucesso do New Deal, do Welfare State, da fase dinâmica da economia brasileira entre 2003 e 2013, e até mais recentemente da "geringonça" portuguesa.

Aqui, ao vermos em que setores e com que atividades estamos por um lado dilapidando os recursos naturais do planeta por excessos de uso, e por outro que insuficiências existem em diversas partes da população, podemos, setor por setor, canalizar os esforços e recursos financeiros para onde irão gerar maior equilíbrio.

Ou seja, podemos calcular onde devemos nos restringir, onde podemos expandir, em que setores há prioridade e assegurar o básico para a população. A economia passa a fazer sentido. Tim Jackson, que comenta o livro, lembra o absurdo de termos sido "persuadidos a gastar dinheiro que não temos em coisas que não precisamos para causar impressões que não irão durar sobre pessoas que não nos importam." Já era tempo que alguém desse um pouco de sentido na visão geral da economia realmente existente. No centro das respostas, não estão modelos complicados, e sim a "capacidade do século 21 de criar formas muito mais efetivas de governança, em cada escala, do que as que têm sido vistas anteriormente." (p. 51). E corrigir as contas, em economia, é fundamental.

\section{Resgatar a utilidade dos recursos financeiros}

As boas intenções, proclamações e declarações de elevados princípios éticos não irão resolver se não enfrentarmos o problema central do dinheiro para financiar o que devemos priorizar. É essencial lembrar, como vimos acima, que a conferência de Paris em 2015, que com pompa e circunstância firmou o compromisso mundial de levantar 100 bilhões de dólares ao ano para enfrentar o desastre ambiental, é uma soma ridícula quando comparada aos 20 trilhões de dólares que se escondem em paraísos fiscais, 200 vezes mais. Lembrando ainda que praticamente todas as grandes corporações e grandes fortunas hoje têm filiais ou contas em paraísos fiscais, essencialmente fruto de evasão fiscal, corrupção e lavagem de dinheiro. O sistema econômico realmente existente está atolado em ilegalidades. E são recursos em gigantescos volumes. 
Um segundo ponto essencial é que o mundo não é pobre. Como vimos, o PIB mundial, atualmente da ordem de 85 trilhões de dólares. Este volume de bens e serviços produzidos no mundo representa 3700 dólares por mês por família de 4 pessoas, cerca de 15 mil reais. Não há nenhuma justificativa para termos 820 milhões de pessoas passando fome, das quais mais de 150 milhões de crianças. Nosso problema não é econômico, é essencialmente ético e político. No caso do Brasil, estamos exatamente na média mundial em termos de PIB por pessoa. Não há nenhuma razão econômica para a pobreza.

Um terceiro ponto é que as fortunas que hoje se acumulam são essencialmente baseadas em remuneração de papéis financeiros. A partir de estudos de Thomas Piketty, Joseph Stiglitz, Paul Krugman, Ellen Brown, Michael Hudson, François Chesnais, Marjorie Kelly, Paul Dembinski, Sam Pizzigati, e tantos outros, formou-se hoje uma sólida base teórica e clara explicitação dos mecanismos especulativos que multiplicam fortunas e extraem os recursos que são indispensáveis para evitar os desastres que temos pela frente.

Lembremos o mecanismo básico do enriquecimento especulativo: um bilionário que aplica um bilião em papéis que rendam modestos $5 \%$ ao ano está ganhando 137 mil dólares ao dia. No dia seguinte a fortuna dele irá render sobre um bilhão mais o ganho do dia anterior e assim por diante, sem precisar produzir nada. O mecanismo, conhecido como snowball effect, efeito bola de neve, levou ao absurdo de $1 \%$ mais ricos que dispõem de mais patrimônio do que os outros $99 \%$. Sem produzir. No Brasil 6 famílias têm mais riqueza acumulada do que o patrimônio da metade mais pobre da população. Isso, evidentemente, não funciona.

Jared Bernstein (2019), que foi conselheiro econômico do vice-presidente dos EUA Joe Biden, constata hoje este deslocamento geral das análises econômicas, com o título expressivo do seu estudo: "Nova economia - Uma geração de economistas ajudou a nos colocar nesta bagunça (mess): uma nova geração pode nos tirar." Segundo autor:

Qualquer forma de análise social que vise ser útil para a sociedade precisa evoluir de maneira a estimular o bem-estar social, a equidade, a justiça racial e de gênero, e a sustentabilidade ambiental. Durante demasiado tempo, grande parte da ciência econômica foi reprovada neste teste - e, no entanto, a sua interação com a classe dirigente a elevou para o nível do poder... O mal causado de maneira penetrante por esta interação abriu caminho para um número crescente de economistas que estão derrubando a velha escola do seu patamar privilegiado. Frente a que eu digo: já era tempo. 
A revista Forbes, na sua edição brasileira, lançou em 2019 uma lista detalhada dos 206 bilionários do país. Jorge Lemann está em primeiro lugar, com patrimônio de 104 bilhões de reais. Atividade bancária, naturalmente, dinheiro ganho intermediando dinheiro dos outros. Em segundo lugar Joseph Safra, também dono de banco, com 95 bilhões, sendo que entre 2018 e 2019 aumentou a sua fortuna em 19,31 bilhões, numa fase de paralisia geral da economia brasileira. A família Marinho, com fortuna de 34 bilhões, teve um aumento de 9,3 bilhões no mesmo período. Cândido Pinheiro Koren de Lima, dos serviços de saúde Hapvida, tem um patrimônio de 13,82 bilhões, fortuna que no último ano aumentou em 6,22 bilhões. Especular com saúde rende muito.

É preciso buscar muito na lista para encontrar alguém que efetivamente produza algo. Preferem deter a gestão dos recursos financeiros, ou gerir fundos de ações. No conjunto, em 7 anos de descontrole do sistema financeiro, passamos no Brasil de 74 bilionários em 2012 para 206 bilionários em 2019. As fortunas acumuladas passaram de 346 bilhões de reais para 1205,8 bilhões no mesmo período. (p. 108) A tentativa da Dilma de frear a especulação reduzindo juros, em 2012/2013, aparece hoje com toda sua fragilidade: o peso político dos interesses financeiros é muito grande. Trata-se do coração do poder. E o travamento da economia torna-se óbvio.

As fortunas mencionadas, evidentemente, não pagam impostos, já que lucros e dividendos distribuídos são isentos, por lei, desde 1995. Não é novo o processo, a expressão pecunia pecuniam parit nos vem dos antigos. Mas com o dinheiro hoje imaterial, essencialmente emitido pelos próprios bancos, e surfando no planeta com pouco controle, o resultado é o desastre planetário. No Brasil, é o sexto ano em que estamos parados, drenados por lucros exorbitantes e improdutivos. Não é muito misteriosa a necessidade das grandes fortunas voltarem a pagar impostos.

As alternativas estão se desenhando. Thomas Piketty propõe medidas para o que seria um "socialismo participativo". Segundo o resumo de Enric Bonet (2019), Piketty sugere

a adoção de uma nova taxação progressiva do patrimônio que levaria em conta o endividamento das famílias e não afetaria aqueles que possuem um nível de propriedade na média do país. Tributariam com o $1 \%$ aqueles cujo patrimônio fosse o dobro da média nacional, com $20 \%$ aqueles que possuíssem uma fortuna 100 vezes superior e com um máximo de $90 \%$ aqueles cujo patrimônio fosse 10.000 vezes superior à média." 
O conjunto de medidas propostas por Piketty, inclusive uma "dotação universal" e um compartilhamento de poder na gestão das corporações, como já acontece na Suécia e na Alemanha, forma uma visão que faz sentido. É interessante notar que Piketty caracteriza as suas propostas como evoluindo para um "socialismo participativo", enquanto Stiglitz, nos seus últimos trabalhos, propõe um "capitalismo progressista". (progressive capitalism). $\mathrm{Na}$ realidade, estamos simplesmente buscando algo que funcione.

Muito interessantes igualmente as propostas de Sam Pizzigatti relativamente à adoção de uma renda máxima nas corporações. Não se trata de sonhos. A ideia consiste em limitar as remunerações dos executivos ao salário-base da empresa. Assim, o andar de cima poderia aumentar o dinheiro que embolsa na medida em que também aumenta a remuneração do andar de baixo. No estado de Oregon, nos EUA, as empresas em que o leque de remuneração ultrapassa 1 para 20, são simplesmente excluídas de participar em contratos com o setor público, e numerosos estados americanos já exigem que as empresas tornem pública a amplitude das remunerações que adotam.

A questão dos paraísos fiscais aparece regularmente na agenda das últimas reuniões do G20, bem como a evasão fiscal generalizada por parte dos grandes grupos e grandes fortunas mundiais. A OCDE prepara uma primeira proposta de regulação financeira internacional, no quadro do BEPS (Base Erosion and Profit Shifting), que deve ver a luz em 2020. Mas a inoperância dos governos e a lentidão dos processos justificam plenamente a indignação de tantos jovens pelo planeta afora, e a perda de paciência de bilhões de pobres que hoje são privados do essencial enquanto os recursos são desviados da sua utilização produtiva, constituindo o que Marjorie Kelly e Ted Howard qualificam adequadamente de 'capitalismo extrativo'. Uma mudança sistêmica em como vemos a economia está na ordem do dia.

\section{Considerações Finais}

Até o tradicional distanciamento e frieza das análises científicas está perdendo espaço. Não podemos senão concordar com esta declaração de Joseph Stiglitz (2019):

O experimento neoliberal - impostos mais baixos para os ricos, desregulamentação dos mercados de trabalho e de produtos, financeirização e globalização - tem sido um fracasso espetacular. O crescimento é menor do que era no quarto de século após a Segunda Guerra Mundial, e a maior parte acumulou-se no topo da escala de renda. Depois de décadas de renda estagnada 
ou mesmo em queda para aqueles abaixo dos mais ricos, o neoliberalismo deve ser declarado morto e enterrado.

Uma evidência começa a chegar até as pessoas mais desinformadas ou ideologicamente mais deformadas: as imensas fortunas especulativas têm de passar a pagar impostos, e o resultado desses impostos deve ser investido no resgate da sustentabilidade do planeta e na redução da desigualdade. E o básico para a sobrevivência dos mais pobres deve ser garantido desde já. Hoje enfrentamos o absurdo de conhecermos os desafios, de sabermos o que deve ser feito, e de termos os recursos financeiros e tecnológicos correspondentes, ao mesmo tempo que simplesmente adiamos as ações a serem tomadas.

Participe da discussão, acessando www.ecofranbr.org e www.francescoeconomy.org

\section{Bibliography}

BERNSTEIN, Jared - New Economics: A Generation of Economists Helped Get Us into This Mess. A New Generation Can Get Us Out. https://www.vox.com/policy-andpolitics/2019/9/13/20862607/economics-inequality-deregulation-wealth-taxes-policy

BONET, Enric - Piketty e o "socialismo participativo" - IHU, outubro 2019 http://dowbor.org/2019/10/piketty-propoe-socialismo-participativo-outras-palavras-20193p.html/

BROWN, Ellen - Banking on the People - Democracy Collaborative, Washington, 2019

Business Round Table - Statement on the Purpose of a Corporation file://C:/Users/Ladislau\%20Dowbor/Downloads/BRT-Statement-on-the-Purpose-of-a-

Corporation-with-Signatures-1.pdf

DOWBOR, Ladislau - A Era do Capital Improdutivo - Autonomia Literária, São Paulo, 2018 - $\quad$ http://dowbor.org/blog/wp-content/uploads/2018/11/Dowbor- -A-ERA-DOCAPITAL-IMPRODUTIVO.pdf

Forbes - 200 bilionários brasileiros - Edição Especial - São Paulo, 2019

KELLY, Marjorie and Ted Howard - The Making of a Democratic Economy - Berrett Koehler Publishers, Oakland, 2019

KLIASS, Paulo - Cheiro de mudanças no ar - Outras Palavras, 24/set. 2019 https://outraspalavras.net/alemdamercadoria/economia-cheiro-de-mudanca-no-ar/ 
PIZZIGATI, Sam - The Case for a Maximum Wage - Polity Press, Cambridge, UK, 2018 - $\quad$ https://dowbor.org/2018/10/sam-pizzigati-the-case-for-a-maximum-wage-polity-presscambridge-uk-2018-133p.html/

RAWORTH, Kate - Doughnut Economics: 7 ways to think like a 21st Century Economist Chelsea Green Publishing, 2017 - (No Brasil: Economia Donut: 7 maneiras de pensar como um economista do século 21) http://dowbor.org/2017/08/kate-raworth-doughnuteconomics-7-ways-to-think-like-a-21st-century-economist-chelsea-green-publishing2017-isbn-a-economia-da-rosquinha-7-maneiras.html/

Roosevelt Institute - New Rules for the $21^{\text {st }}$ Century - 2019 https://dowbor.org/2019/04/roosevelt-institute-new-rules-for-the-21st-century-201977p.html/

STIGLITZ, Joseph - Hora de enterrar um sistema fracassado - Outras Palavras, 6 de jun. 2019 https://outraspalavras.net/crise-civilizatoria/stiglitz-hora-de-enterrar-um-sistemafracassado/

http://dowbor.org/2019/06/stiglitz-hora-de-enterrar-um-sistema-fracassado-outraspalavras-traducao-jun-2019-3p.html/

STIGLITZ, Joseph - Crise Civilizatória - 4 Set. 2019 - https://outraspalavras.net/crisecivilizatoria/poderia-o-capitalismo-ser-menos-brutal//

WALLACE-WELLS, David - The uninhabitable earth - Penguin Books, New York 2019 https://dowbor.org/2019/07/david-wallace-wells-the-uninhabitable-earth-life-afterwarming-tim-duggan-books-penguin-new-york-2019.html//

\section{Ladislau Dowbor \\ São Paulo, São Paulo, Brasil. \\ Minicurrículo:}

Professor titular de economia da PUC-SP, consultor de várias agências da ONU, e autor de numerosos livros e estudos técnicos disponíveis em http://dowbor.org em regime Creative Commons (livre uso não-comercial). Contato

Email: ldowbor@gmail.com

Link do Lattes: http://dowbor.org

Recebimento: 15/11/2019

Aprovacão: 20/11/2019

\section{Q.Code}

\section{Editores-Responsáveis}

Prof. Dr. Enéas de Araújo Arrais Neto, Universidade Federal do Ceará - UFC, Brasil Dr. Sebastien Pesce, Universidade de Orléans, França 